\title{
AVALIAÇÃO DA EFETIVIDADE EM UNIDADES DE CONSERVAÇÃO: UM ESTUDO DE CASO NO
} ESTADO DO MARANHÃO, BRASIL

\section{Evaluation of effectiveness in conservation units: a case study in the state of Maranhão, Brazil}

\author{
Yata Anderson Gonzaga Masullo \\ Instituto Maranhense de Estudos Socioeconômicos e Cartográficos - IMESC \\ yanderson3@hotmail.com \\ Helen da Costa Gurgel \\ Universidade de Brasília - UNB \\ helengurgel@unb.br \\ Anne-Elizabeth Laques \\ Institut de Recherche pour le Développement (IRD) \\ anne-elizabeth.laques@ird.fr \\ Dionatan Silva Carvalho \\ Instituto Maranhense de Estudos Socioeconômicos e Cartográficos - IMESC \\ dionatan.carvalho@uol.com.br
}

Artigo enviado para publicação em 26/05/2020 e aceito em 16/09/2020

DOI: $10.12957 /$ tamoios.2020.51272

\section{Resumo}

As áreas protegidas possuem grande importância na manutenção do ambiente saudável para as pessoas e a natureza. Eles são essenciais para a conservação da biodiversidade e vital para as culturas e meios de subsistência das comunidades tradicionais (UNEP; WCMC; IUCN, 2018). Nesse contexto, o presente estudo propõe a avaliação da efetividade de unidades de conservação do Maranhão, Brasil, a partir do IFUC- Índice de Efetividade das Unidades de Conservação. Busca-se dessa forma, apresentar novas perspectiva para a otimização da avaliação do nível de efetividade das áreas protegidas em escala regional. Os procedimentos técnicos aplicados foram divididos em 3 etapas: 1) Revisão bibliográfica e coleta de indicadores primários e secundários; 2) Qualificação e sintetização das variáveis com base no método de Analytic Hierarchy Process (AHP) e 3) Modelagem do IFUC. Entre os resultados alcançados, observou-se que conforme o método proposto $18 \%$ das UCs em análise apresentaram nível satisfatório, $46 \%$ grau medianamente satisfatório, enquanto $9 \%$ pouco satisfatório e $27 \%$ nível de efetividade insatisfatório. A avaliação da efetividade das UCs do Maranhão, demonstrou como as diferentes características e fenômenos ambientais, culturais, econômicos, sociais e políticos interagem e influenciam a dinâmica da paisagem local.

Palavras chaves: Áreas Protegidas; Efetividade; Maranhão.

\begin{abstract}
Protected areas are of great importance in maintaining a healthy environment for people and nature. They are essential for the conservation of biodiversity and vital for the cultures and livelihoods of traditional communities (UNEP; WCMC; IUCN, 2018). In this context, the present study proposes the evaluation of the effectiveness of conservation units in Maranhão, Brazil, based on the IFUC- Index of Effectiveness of Conservation Units. In this way, it seeks to present new perspectives for the optimization of the assessment of the level of effectiveness of protected areas on a regional scale. The technical procedures applied were divided into 3 stages: 1) Literature review and collection of primary and secondary indicators; 2) Qualification and synthesis of variables based on the Analytic Hierarchy Process (AHP) method and 3) IFUC modeling. Among the results achieved, it was observed that, according to the proposed method, $18 \%$ of the UCs under analysis had a satisfactory level, $46 \%$ were moderately satisfactory, while $9 \%$ were unsatisfactory and $27 \%$ were unsatisfactory. The evaluation of the effectiveness of the UCs in Maranhão, demonstrated how the different characteristics and environmental, cultural, economic, social and political phenomena interact and influence the dynamics of the local landscape.
\end{abstract}

Keywords: Protected Areas; Effectiveness; Maranhão. 


\section{Introdução}

As áreas protegidas (APs) são reconhecidas como territórios com limites geográficos definidos e reconhecidos, com o intuito de conservar a natureza e o patrimônio cultural (Mcnelly, 2004). Atualmente, registra-se 238 mil APs designadas em 244 países abrangendo aproximadamente 14,9\% da superfície terrestre e 7,3\% da área oceânica global (UNEP-WCMC e IUCN, 2018). No entanto, não podemos considerar somente a cobertura das APs como uma medida da efetividade ou mesmo do sucesso da conservação, para tanto, faz-se necessário considerar o contexto, nível de representatividade, conectividade e as condições adequadas de infraestrutura (Artaza-Barrios e Schiavetti, 2007).

Refletindo sobre a temática Hockings et al. (2015) entendem como uma AP efetiva, quando esta possui capacidade e competências particulares, que permitam cumprir satisfatoriamente com as funções para as quais foi criada. Geldmann et al. (2014), complementam esse entendimento afirmando que uma AP pode ser considerada como efetiva, quando esta alcança seus objetivos em relação a manutenção da integridade e resiliência, de modo a garantir a representatividade e viabilidade de todos os níveis de organização da biodiversidade. Para Silva (2016), a efetividade na gestão desses territórios, refere-se ao êxito da AP em relação à conservação, à manutenção dos valores da biodiversidade e à sustentabilidade no uso dos recursos naturais.

De acordo com o relatório desenvolvido pela UNEP-WCMC e IUCN (2018), verifica-se que o percentual de APs com gestão avaliadas como "efetivas" ou "altamente eficazes" reduziu de 54\% em 2014 para 48\% em 2017. Infere-se a avaliação da efetividade das APs, o objetivo de mensurar o grau de eficiência, ou seja, o quão bem é gerenciado e qual extensão do que se pretende conservar, concentrando-se nos resultados e metas (Hockings et al., 2015). Complementando Watts (2016) afirma que para se avaliar a efetividade das APs, deve-se analisar a capacidade desta, em executar as ações relacionadas com seus objetivos de promover a conservação e proteção da natureza e do patrimônio cultural.

Como estrato dessa realidade, o Brasil ao se considerar as unidades de conservação - UC como um subconjunto das áreas protegidas, verifica-se cerca de 998 sob governança federal, 908 estadual e 295 com jurisdição municipal, distribuídas em aproximadamente $18 \%$ território brasileiro (MMA, 2018). Conforme o CNUC/MMA (2018), 61,6\% do total das UCs do Brasil estão localizadas na área continental (UC Proteção Integral - 684 / UC Uso Sustentável - 1496), já na faixa marinha do país, situam-se 38,4\% (UC Proteção Integral - 73 / UC Uso Sustentável $-104)$.

Para Geldmann et al. (2014), mudar essa realidade passa pela ampliação da coleta e análise de dados que permitam a construção de metodologias para analisar a efetividade dessas APs. Contudo, Nelson e Chomitz (2011) ressaltam que as ferramentas (WWF,1999), Padovan (2003), Ervin (2006), Stolton et al. (2007), Marinelli (2011), ICMBIO/WWF (2011) e WWF (2017) até o momento desenvolvidas, de modo geral para esse tipo de avaliação apresentam dificuldades em estabelecer correlação entre indicadores mensuráveis e não mensuráveis, além de serem baseadas principalmente em dados primários de alta subjetividade, com significativos custos operacionais e obstáculos para avaliações periódicas. Sob essa perspectiva Moreaux et al. (2018), ressalta a importância de iniciativas que busquem simplificar e ao mesmo tempo aprimorar as técnicas existentes, principalmente no que tange ao âmbito regional e local.

Nesse contexto, este artigo propõe a avaliação da efetividade de unidades de conservação do Maranhão, a partir do IFUC- Índice de Efetividade das Unidades de Conservação. Tendo como área de estudo um estado em forte transformação socioambiental do Brasil. Localizado na região norte-nordeste do Brasil, o Estado do Maranhão situa-se na zona de transição entre o bioma Amazônico e o Cerrado brasileiro. Isso lhe atribui grande diversidade morfológica e ambiental, com clima semiárido na faixa Nordeste e úmido equatorial na região da Amazônia. 
Nesse contexto, o presente estudo incialmente apresenta os procedimentos técnicos utilizados para construção da metodologia aplicada e, em seguida, analisa-se o nível de efetividade das unidades de conservação em estudo do Maranhão. Onde encontram-se 15 UCs estaduais e 14 UCs federais. Entre as UCs do estado, verifica-se a presença de 18 UCs com características de uso sustentável e 11 com nível de proteção integral, abrangendo cerca de 93 mil km² ou $28 \%$ do território do Estado.

\section{MATERIAIS E MÉTODOS}

\section{Área de Estudo}

A pesquisa possui como objeto de estudo $11 \mathrm{UCs}$ do Maranhão. Entre as UCs selecionadas, estão 3 UCs estaduais com proteção integral e 8 UCs federais (três de proteção integral e cinco de uso sustentável). Esses territórios protegidos, foram criados com a finalidade de proteger áreas de grande relevância socioambiental e cultural, tanto do bioma Amazônico quanto do Cerrado, abrangendo atualmente 21 municípios e área de aproximadamente 13.809 $\mathrm{km}^{2}$, que correspondem a 4,2\% do território estadual.

Visando ampliar a disponibilidade e rastreabilidade dos dados, bem como viabilizar os trabalhos de campo, foram consideradas UCs criadas até o ano de 2010 (ano base utilizado para sintetização dos indicadores), que possuem o território totalmente inserido no Maranhão e que não contam com a área sobreposta por outras UCs. Ressalta-se que entre as UCs selecionadas, não foi possível considerar as unidades reconhecidas como Áreas de Proteção Ambiental APA, tendo em vista a grande extensão territorial e a sobreposição dos limites de parte destas UCs. Essas características inviabilizaram os trabalhos de campo para coleta e validação dos dados, necessários para aplicação e testes iniciais da metodologia proposta, considerando os recursos financeiro disponíveis (Quadro 1 e Figura 1). 


\begin{tabular}{|c|c|c|c|c|c|c|}
\hline $\begin{array}{l}\text { Unidade de } \\
\text { Conservação }\end{array}$ & Criação & $\begin{array}{l}\text { Nível de } \\
\text { Proteção }\end{array}$ & Bioma & Área & Objetivo & Municípios (MA) \\
\hline $\begin{array}{c}\text { Parque Estadual } \\
\text { do Bacanga }\end{array}$ & $\begin{array}{l}\text { Lei Estadual } N^{\circ} 7.545 \\
\text { de } 02 / 03 / 1980\end{array}$ & $\begin{array}{c}\text { Proteção } \\
\text { Integral }\end{array}$ & Amazônia & $26 \mathrm{~km}^{2}$ & $\begin{array}{c}\text { Proteger a margem direita } \\
\text { do Rio Bacanga e a Bacia } \\
\text { do Maracanã }\end{array}$ & São Luís \\
\hline $\begin{array}{l}\text { Parque Estadual } \\
\text { do Mirador }\end{array}$ & $\begin{array}{c}\text { Lei Estadual } N^{\circ} 7.641 \\
\text { de } 04 / 06 / 1980, \\
\text { alterado pela Lei } \\
\text { Estadual no } 8.958 \text { de } \\
08 / 05 / 2009\end{array}$ & $\begin{array}{c}\text { Proteção } \\
\text { Integral }\end{array}$ & Cerrado & $\begin{array}{c}4.370 \\
\mathrm{~km}^{2}\end{array}$ & $\begin{array}{l}\text { Proteger as nascentes dos } \\
\text { rios Alpercatas e Itapecuru } \\
\text { (principal fonte de } \\
\text { abastecimento de água da } \\
\text { capital maranhense) }\end{array}$ & $\begin{array}{c}\text { Mirador, Formosa } \\
\text { da Serra Negra }\end{array}$ \\
\hline $\begin{array}{l}\text { Parque Estadual } \\
\text { do Sítio do } \\
\text { Rangedor }\end{array}$ & $\begin{array}{l}\text { Lei Estadual } \mathrm{N}^{\circ} \\
21.797 \text { de } 15 / 12 / 2005, \\
\text { alterado pela Lei } \\
\text { Estadual } \mathrm{N}^{\circ} \\
10.455 / 2016\end{array}$ & $\begin{array}{l}\text { Proteção } \\
\text { Integral }\end{array}$ & Amazônia & $\begin{array}{c}1,3 \\
\mathrm{~km}^{2}\end{array}$ & $\begin{array}{l}\text { Preservar remanescentes } \\
\text { florestais de São Luís, } \\
\text { funcionando como } \\
\text { importante área verde e } \\
\text { corredor ecológico. }\end{array}$ & São Luís \\
\hline $\begin{array}{l}\text { Parque Nacional } \\
\text { dos Lençóis } \\
\text { Maranhenses }\end{array}$ & $\begin{array}{c}\text { Lei Federal } N^{\circ} 86.060 \\
\text { de } 02 / 06 / 1981\end{array}$ & $\begin{array}{c}\text { Proteção } \\
\text { Integral }\end{array}$ & Cerrado & $\begin{array}{l}1.550 \\
\mathrm{~km}^{2}\end{array}$ & $\begin{array}{l}\text { Preservar o ecossistema de } \\
\text { dunas, mangues e restinga } \\
\text { do litoral oriental do Estado }\end{array}$ & $\begin{array}{l}\text { Barreirinhas, } \\
\text { Santo Amaro e } \\
\text { Primeira Cruz }\end{array}$ \\
\hline $\begin{array}{c}\text { Parque Nacional } \\
\text { da Chapada das } \\
\text { Mesas }\end{array}$ & $\begin{array}{c}\text { Decreto Federal s/n de } \\
12 / 12 / 2005\end{array}$ & $\begin{array}{c}\text { Proteção } \\
\text { Integral }\end{array}$ & Cerrado & $\begin{array}{l}1.600 \\
\mathrm{~km}^{2}\end{array}$ & $\begin{array}{c}\text { Proteção da fauna, flora, } \\
\text { cachoeiras e sítios } \\
\text { arqueológicos } \\
\text { caracterizados pela presença } \\
\text { de pinturas rupestres. }\end{array}$ & $\begin{array}{c}\text { Carolina, Riachão } \\
\text { e Estreito }\end{array}$ \\
\hline $\begin{array}{c}\text { Reserva } \\
\text { Biológica do } \\
\text { Gurupi }\end{array}$ & $\begin{array}{c}\text { Lei Federal } N^{\circ} 95.614 \\
\text { de } 12 / 01 / 1988\end{array}$ & $\begin{array}{c}\text { Proteção } \\
\text { Integral }\end{array}$ & Amazônia & $\begin{array}{c}2.712 \\
\mathrm{~km}^{2}\end{array}$ & $\begin{array}{l}\text { Proteger remanescentes da } \\
\text { fauna e flora amazônicos } \\
\text { existente no Estado. } \\
\text { Preservar as serras do } \\
\text { Tiracambu e da Desordem, } \\
\text { onde localizam-se nascentes } \\
\text { dos rios Gurupi e Pindaré. }\end{array}$ & $\begin{array}{l}\text { Bom Jardim, São } \\
\text { João do Carú e } \\
\text { Centro Novo }\end{array}$ \\
\hline $\begin{array}{c}\text { Reserva } \\
\text { Extrativista do } \\
\text { Quilombo do } \\
\text { Frechal }\end{array}$ & $\begin{array}{l}\text { Decreto Federal s/n } \\
534 \text { de } 21 / 05 / 1992\end{array}$ & $\begin{array}{c}\text { Uso } \\
\text { Sustentável }\end{array}$ & Amazônia & $9 \mathrm{~km}^{2}$ & $\begin{array}{l}\text { Garantir o uso sustentável } \\
\text { dos recursos naturais } \\
\text { explorados pelas } \\
\text { comunidades extrativistas, } \\
\text { preservando a cultura local } \\
\text { dos quilombolas. }\end{array}$ & Mirinzal \\
\hline $\begin{array}{c}\text { Reserva } \\
\text { Extrativista do } \\
\text { Cururupu }\end{array}$ & $\begin{array}{c}\text { Decreto Federal S/N } \\
\text { de } 03 / 06 / 2004\end{array}$ & $\begin{array}{c}\text { Uso } \\
\text { Sustentável }\end{array}$ & Amazônia & $\begin{array}{l}1.850 \\
\mathrm{~km}^{2}\end{array}$ & $\begin{array}{l}\text { Proteger o modo de vida das } \\
\text { comunidades locais e } \\
\text { assegurar a preservação de } \\
\text { parte das Reentrâncias } \\
\text { Maranhenses. }\end{array}$ & $\begin{array}{l}\text { Cururupu, } \\
\text { Serrano do } \\
\text { Maranhão, } \\
\text { Apicum Açu e } \\
\text { Bacuri }\end{array}$ \\
\hline $\begin{array}{c}\text { Reserva } \\
\text { Extrativista do } \\
\text { Ciriacó }\end{array}$ & $\begin{array}{c}\text { Decreto Federal } \\
\mathrm{N}^{\circ} 534 \text { de } 20 / 05 / 1992 \\
\text { alterado por Decreto } \\
\text { S/N 17/06/2010 }\end{array}$ & $\begin{array}{c}\text { Uso } \\
\text { Sustentável }\end{array}$ & Amazônia & $8 \mathrm{~km}^{2}$ & $\begin{array}{c}\text { Assegurar a conservação } \\
\text { dos recursos naturais } \\
\text { renováveis, proteger os } \\
\text { babaçuais e a cultura da } \\
\text { população extrativista local. }\end{array}$ & Cidelândia \\
\hline $\begin{array}{c}\text { Reserva } \\
\text { Extrativista da } \\
\text { Mata Grande }\end{array}$ & $\begin{array}{l}\text { Decreto Federal s/n } \\
532 \text { de 20/05/1992 }\end{array}$ & $\begin{array}{c}\text { Uso } \\
\text { Sustentável }\end{array}$ & Amazônia & $11 \mathrm{~km}^{2}$ & $\begin{array}{l}\text { Conservar os recursos } \\
\text { naturais renováveis, } \\
\text { proteger os babaçuais e a } \\
\text { cultura da população } \\
\text { extrativista local. }\end{array}$ & $\begin{array}{l}\text { Senador La } \\
\text { Roque e } \\
\text { Davinópolis }\end{array}$ \\
\hline $\begin{array}{c}\text { Reserva } \\
\text { Extrativista da } \\
\text { Chapada Limpa }\end{array}$ & $\begin{array}{l}\text { Decreto Federal s/n } \\
536 \text { de } 21 \text { de maio de } \\
1992\end{array}$ & $\begin{array}{c}\text { Uso } \\
\text { Sustentável }\end{array}$ & Cerrado & $\begin{array}{l}120 \\
\mathrm{~km}^{2}\end{array}$ & $\begin{array}{l}\text { Garantir as práticas } \\
\text { extrativistas locais e a } \\
\text { preservação dos } \\
\text { bacurizeiros. }\end{array}$ & Chapadinha \\
\hline
\end{tabular}

Quadro 1 - Caracterização das Unidade de Conservação em estudo. Fonte: ICMBIO; SEMA (2016); Masullo (2018b). 


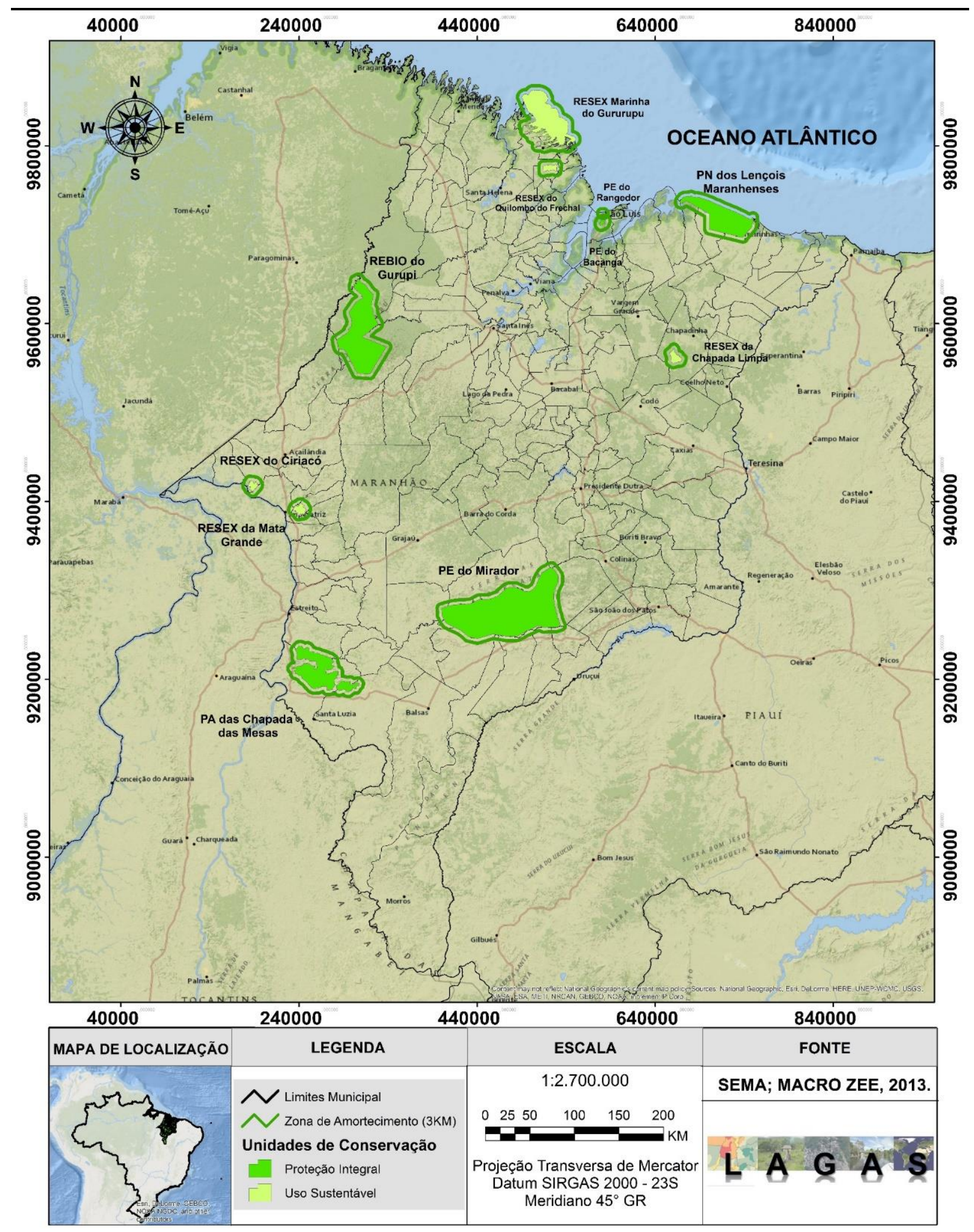

Figura 1 - Mapa de Localização das UCs em estudo no Maranhão.

\section{Abordagem Metodológica}

A proposta metodológica do estudo, desenvolve-se sob uma abordagem sistêmica e multidisciplinar. Considera-se para tanto, a análise de variáveis primárias e secundárias selecionadas com base em sua disponibilidade, confiabilidade e periodicidade de atualização dos dados, estando estes interligados aos elementos globais de efetividade (contexto, planejamento, insumos, resultados e processos) ${ }^{1}$ (Hockings et al., 2015). 


\section{Procedimentos Metodológicos}

O estudo foi baseado nas fases de seleção, coleta, processamento, validação, modelagem e análise dos dados seguindo abordagem indicada por Oestreicher et al. (2009). Os procedimentos executados estruturam-se em 3 etapas:

Etapa 1: Definiu-se os princípios, critérios e indicadores por meio da realização de revisão bibliográfica sobre a temática e entrevistas. As entrevistas realizadas tiveram característica informais, sendo estas consideradas do tipo guiada ${ }^{2}$ e semidiretivas $^{3}$ com o objetivo de testar, aprofundar e validar as hipóteses do estudo (Cohen et al., 2007). Essas entrevistas tiveram como foco os gestores das secretarias estaduais e municipais de meio ambiente e ICMBio correspondente as $11 \mathrm{UCs}$ em estudo, representantes dos conselhos participativos (Meio Ambiente e Cidades) e pesquisadores de instituições de pesquisa (IMESC, INCID e IBGE) e universidades (UFMA; UEMA e IFMA), além de abranger a comunidade local.

A análise da literatura, legislação, manuais e estudos técnicos aplicados contribuíram para a definição de variáveis que possibilitaram a formulação de indicadores e dos índices. Esses foram divididos em quatro dimensões, com base em Padovan (2001) e Stoll-Kleemann (2010):

- Dimensão institucional se refere à capacidade de governança para lidar com os problemas e desafios ambientais e sociais, a partir dos instrumentos de gestão disponíveis;

- Dimensão ambiental refere-se ao nível de conservação e alteração da paisagem;

- Dimensão social considera-se a pressão exercida pela população que reside dentro da unidade e no seu entorno, bem como o nível e a capacidade de participação e integração da comunidade a médio e longo prazo, com a gestão da UC;

- Dimensão econômica, representa o nível de desenvolvimento econômico e a pressão exercida sob a área protegida.

Etapa 2: Foi baseada na coleta dos dados e construção dos indicadores para as dimensões definidas na etapa 1.

A obtenção dos dados de fontes primárias (quantidade de recursos humanos, infraestrutura, situação fundiária, ações de manejo, conflitos e práticas turísticas), foram baseadas em questionários e em entrevista com os gestores e a comunidade local. Para tal, realizou-se visitas as 11 UCs no período de 2016 e 2018, onde foram aplicados questionários para obtenção de dados e entrevistas para obtenção de informações para mapear os conflitos e agentes tensores locais.

Os trabalhos de campo, tiveram também como objetivo obter dados para validar os resultados obtidos por imagens de satélite. Para isso, realizou-se fotografias das áreas de estudos através de drone (DJI Phanton 4 Pro Plus) e GPS etrex 30, para construção de banco de dados de imagens para realizar as análises de validação de verdade de campo dos mapeamentos que foram realizados.

Em relação aos dados secundários, estes foram selecionados de acordo com a disponibilização de estatísticas existentes em nível de município e de setor censitário. Utilizouse o ano de 2010 como base, considerando a atualização dos dados desenvolvida pelo censo do Instituto Brasileiro de Geografia e Estatística - IBGE. Os dados selecionados foram cedidos por meio de instituições públicas e de pesquisa, como o Instituto Brasileiro de Estatística e Geografia - IBGE, Instituto Chico Mendes de Conservação da Biodiversidade - ICMBio, Instituto de Pesquisa Econômica Aplicada - IPEA, Instituto Maranhense de Estudos Socioeconômicos e Cartográficos - IMESC, Secretaria Estadual de Meio Ambiente - SEMA, além de dados extraídos a partir de processamento de imagens de satélite. A coleta dos dados 
secundários (imagens de satélite, densidade demográfica, renda, atualização de planos de manejo, áreas prioritárias para conservação, atividades e economia local) ocorreu através de sites e portais online destas instituições.

O quadro 2 a seguir, apresenta a valoração dos indicadores, com base na escala de comparadores utilizada, ocorreu considerando o levantamento bibliográfico, alinhado ao consenso obtido juntamente com gestores das UCs, representantes de conselhos participativo e pesquisadores de instituições de pesquisa e universidades do Maranhão.

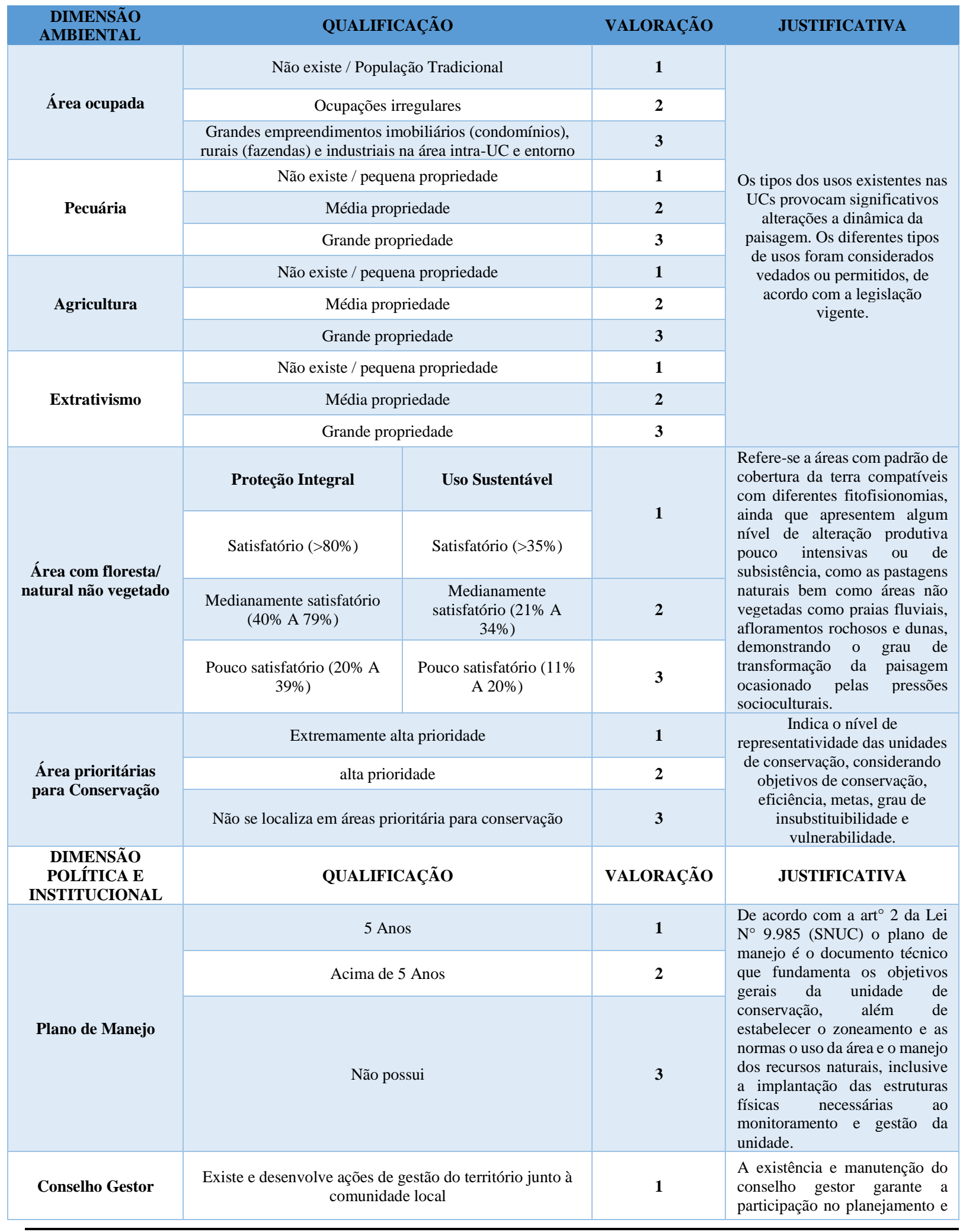




\begin{tabular}{|c|c|c|c|}
\hline & $\begin{array}{l}\begin{array}{l}\text { Existe e não desenvolve nenhum tipo de ações de gestão } \\
\text { do território }\end{array}\end{array}$ & 2 & $\begin{array}{l}\text { na gestão de representantes de } \\
\text { órgãos públicos e da sociedade }\end{array}$ \\
\hline & Não existe & 3 & $\begin{array}{l}\text { civil, ampliando } \\
\text { monitoramento e fiscalização } \\
\text { das UCs em escala local e } \\
\text { regional. }\end{array}$ \\
\hline \multirow{3}{*}{$\begin{array}{l}\text { Secretaria de Meio } \\
\text { Ambiente }\end{array}$} & $\begin{array}{c}\text { Sim existe (Desenvolve projetos e atua no monitoramento } \\
\text { e fiscalização) }\end{array}$ & 1 & \multirow{3}{*}{$\begin{array}{l}\text { A existência Secretaria } \\
\text { Municipal de Meio Ambiente } \\
\text { demonstra um instrumento que } \\
\text { amplia o ordenamento territoria } \\
\text { na área de entorno da UC, bem } \\
\text { como aumenta o monitoramento } \\
\text { e a fiscalização das Unidades de } \\
\text { Conservação em níve } \\
\text { municipal. }\end{array}$} \\
\hline & Estrutura em Conjunto com outra Secretaria (SIM) & 2 & \\
\hline & Não existe & 3 & \\
\hline \multirow{3}{*}{ Situação Fundiária } & Executada & 1 & \multirow{3}{*}{$\begin{array}{l}\text { Indica se a situação fundiária } \\
\text { da UC está de acordo com a } \\
\text { legislação vigente. }\end{array}$} \\
\hline & Parcialmente executada & 2 & \\
\hline & Não executada & 3 & \\
\hline \multirow{3}{*}{ Desenho da UC } & Satisfaz & 1 & \multirow{3}{*}{$\begin{array}{c}\text { Indica se a localização e os } \\
\text { limites da UC são coerentes } \\
\text { com os seus objetivos }\end{array}$} \\
\hline & Satisfaz parcialmente e & 2 & \\
\hline & Não satisfaz & 3 & \\
\hline \multirow{3}{*}{$\begin{array}{l}\text { Recursos Humanos e } \\
\text { Infraestrutura }\end{array}$} & Satisfaz & 1 & \multirow{3}{*}{$\begin{array}{l}\text { Indica se a estrutura da UC } \\
\text { possibilita a realização de ações } \\
\text { de manejo adequados a } \\
\text { categoria e demandas } \\
\text { existentes na UC. }\end{array}$} \\
\hline & Satisfaz parcialmente e & 2 & \\
\hline & Não satisfaz & 3 & \\
\hline \multirow{3}{*}{ Ações de manejo } & Satisfaz & 1 & \multirow{3}{*}{$\begin{array}{c}\text { Indica se ações de manejo estão } \\
\text { de acordo com o Plano de } \\
\text { Manejo e as demandas } \\
\text { existentes na UC. }\end{array}$} \\
\hline & Satisfaz parcialmente & 2 & \\
\hline & Não satisfaz & 3 & \\
\hline \multirow{3}{*}{$\begin{array}{l}\text { Capacidade de } \\
\text { monitoramento e } \\
\text { fiscalização }\end{array}$} & Satisfaz & 1 & \multirow{3}{*}{$\begin{array}{c}\text { Indica se a capacidade de } \\
\text { monitoramento e fiscalização } \\
\text { atende as demandas existentes } \\
\text { na UC. }\end{array}$} \\
\hline & Satisfaz parcialmente e & 2 & \\
\hline & Não satisfaz & 3 & \\
\hline $\begin{array}{l}\text { DIMENSÃO } \\
\text { SOCIAL }\end{array}$ & QUALIFICAÇÃO & VALORAÇÃO & JUSTIFICATIVA \\
\hline \multirow{3}{*}{$\begin{array}{c}\text { Densidade } \\
\text { Demográfica }\end{array}$} & $<4 \mathrm{hab} / \mathrm{km}^{2}$ & 1 & \multirow{3}{*}{$\begin{array}{l}\text { Indica se o grau de ocupação } \\
\text { existentes na UC, está alinhado } \\
\text { com o seu nível de proteção. }\end{array}$} \\
\hline & 4hab/km² A 15 hab/km²) & 2 & \\
\hline & Acima de $15 \mathrm{hab} / \mathrm{km}^{2}$ & 3 & \\
\hline \multirow{3}{*}{$\begin{array}{l}\text { Mediação de } \\
\text { Conflitos }\end{array}$} & Conflitos resolvidos pela existência da UC & 1 & \multirow{3}{*}{$\begin{array}{l}\text { Indica se a UC possibilita a } \\
\text { redução dos conflitos sociais na } \\
\text { região onde está inserida. }\end{array}$} \\
\hline & Conflitos mediados pela existência da UC & 2 & \\
\hline & $\begin{array}{c}\text { Conflitos entre usuários e gestores impedem o manejo } \\
\text { adequado da UC }\end{array}$ & 3 & \\
\hline $\begin{array}{l}\text { DIMENSÃO } \\
\text { ECONÔMICA }\end{array}$ & QUALIFICAÇÃO & VALORAÇÃO & JUSTIFICATIVA \\
\hline \multirow{3}{*}{$\begin{array}{l}\text { Percentual da } \\
\text { população na } \\
\text { Pobreza }\end{array}$} & $(<5 \%)$ & 1 & \multirow{3}{*}{$\begin{array}{l}\text { Indica se a UC possibilita a } \\
\text { redução da vulnerabilidade } \\
\text { social e a maior distribuição de } \\
\text { renda dos habitantes da UC. }\end{array}$} \\
\hline & $5 \% \mathrm{~A} 10 \%$ & 2 & \\
\hline & Acima $10 \%$ & 3 & \\
\hline \multirow{3}{*}{ Economia Local } & Agricultura familiar & 1 & \multirow{3}{*}{$\begin{array}{l}\text { Indica se o tipo de atividade } \\
\text { econômica predominante na } \\
\text { região onde está inserida a UC, } \\
\text { está alinhada com seus } \\
\text { objetivos e metas. }\end{array}$} \\
\hline & Modelo agroexportador & 2 & \\
\hline & Modelo Industrial & 3 & \\
\hline \multirow{3}{*}{ Prática Turísticas } & Visitação com ordenamento & 1 & \multirow{3}{*}{$\begin{array}{c}\text { Indica se as práticas turísticas } \\
\text { estão alinhadas com o Plano de } \\
\text { Manejo da UC }\end{array}$} \\
\hline & Não existe visitação ou pontual & 2 & \\
\hline & Visitação sem ordenamento & 3 & \\
\hline
\end{tabular}

Etapa 3: Nessa etapa, foram empregados análises estatísticas para modelagem dos indicadores levantados para construir o "Índice de Efetividade das Unidades de Conservação" 
(IFUC). Para facilitar as análises foram também criados dois subíndices, para compor o IFUC: o "Índice de Conservação Ambiental (ICA)" e o "Índice de Desenvolvimento Socioeconômico" (IDS). O ICA é composto pelas dimensões ambientais e institucionais, possui o objetivo de avaliar se os tipos de usos e a estrutura de governança das UCs, são adequados ao nível de proteção da área protegida e permitem o alcance dos serviços ecossistêmicos da UC. Enquanto que o IDS é composto pelas dimensões sociais e econômicas, este avalia se a dinâmica social e econômica está alinhada com os objetivos da área protegida, bem como se a UC possibilita a melhora na qualidade de vida da população.

As análises estatísticas para sintetização dos indicadores foram aplicados após a qualificação dos indicadores e para tal utilizou-se o método de Analytic Hierarchy Process (AHP) (Saaty, 1991). O método AHP, consiste em um método multicritérios de modelagem de dados, que permite a ponderação de diversos fatores envolvidos em processos de diagnósticos e tomadas de decisão, auxiliando a integração objetiva de indicadores (Argyriou et al., 2016). Como resultado do AHP, obteve-se a categorização e ponderação de matrizes de comparação para cada nível, com a definição do grau de importância das variáveis, seguindo a escala de comparadores indicada por Saaty et al. (1991) (Quadro 3). Utilizou-se o software IBM SPSS Statistics Base 22.0 e Excel 2018 para a aplicação do método AHP.

\begin{tabular}{|cc|}
\hline VALORES & IMPORTÂNCIA MÚtUA \\
\hline $1 / 9$ & Extremamente menos importante que \\
\hline $1 / 7$ & Muito menos importante que \\
\hline $1 / 5$ & Fortemente menos importante que \\
\hline $1 / 3$ & Moderadamente menos importante que \\
\hline 1 & Igualmente importante a \\
\hline 3 & Moderadamente mais importante que \\
\hline 5 & Fortemente mais importante que \\
\hline 9 & Euito fortemente mais importante que \\
& Quadro 3 - Escala de Comparadores do método AHP. \\
& Fonte: Saaty et al. (1991).
\end{tabular}

Como resultado do método AHP foi possível definir a significância de cada indicador com sua soma igual a 1, bem como sintetização e combinação ponderada dos indicadores. Para a sintetização dos indicadores desenvolve-se uma matriz com base na escala de comparação, visando estabelecer linearmente a hierarquia de importância entre os indicadores definidos (Figuras 2 e 3 ). 


\begin{tabular}{|c|c|c|c|c|c|c|c|c|c|c|c|c|c|c|c|c|c|c|c|}
\hline VARIAVÉIS & $\begin{array}{c}\text { Área com } \\
\text { Floresta / } \\
\text { Natural } \\
\text { não } \\
\text { Vegetado }\end{array}$ & $\begin{array}{c}\text { Área } \\
\text { Ocupada }\end{array}$ & Pecuária & Agricultura & $\begin{array}{c}\text { Extrativis } \\
\text { mo }\end{array}$ & $\begin{array}{c}\text { Área } \\
\text { prioritárias } \\
\text { para } \\
\text { Conservação }\end{array}$ & $\begin{array}{c}\text { Plano } \\
\text { de } \\
\text { Manejo }\end{array}$ & $\begin{array}{c}\text { Conselho } \\
\text { Gestor }\end{array}$ & $\begin{array}{c}\text { Secretaria } \\
\text { Municipal } \\
\text { de Meio } \\
\text { Ambiente }\end{array}$ & $\begin{array}{l}\text { Situação } \\
\text { Fundiária }\end{array}$ & $\begin{array}{c}\text { Desenho } \\
\text { da UC }\end{array}$ & $\begin{array}{l}\text { Recursos } \\
\text { Humanos e } \\
\text { Infraestrut } \\
\text { ura }\end{array}$ & $\begin{array}{c}\text { Ações } \\
\text { de } \\
\text { Manejo }\end{array}$ & $\begin{array}{c}\text { Capacidade } \\
\text { de } \\
\text { Monitorame } \\
\text { nto e } \\
\text { fiscalização }\end{array}$ & $\begin{array}{c}\text { Densidade } \\
\text { Demográfica }\end{array}$ & $\begin{array}{l}\text { Mediação } \\
\text { de } \\
\text { Conflitos }\end{array}$ & $\begin{array}{l}\text { Extrema } \\
\text { Pobreza }\end{array}$ & $\begin{array}{c}\text { Economia } \\
\text { Local }\end{array}$ & $\begin{array}{l}\text { Práticas } \\
\text { Turísticas }\end{array}$ \\
\hline Área com floresta/ natural não vegetado & 1 & $1 / 3$ & $1 / 3$ & $1 / 3$ & 3 & $1 / 9$ & $1 / 5$ & $1 / 5$ & 3 & $1 / 3$ & $1 / 9$ & $1 / 3$ & $1 / 5$ & $1 / 5$ & 3 & $1 / 5$ & 3 & $1 / 9$ & 3 \\
\hline \multirow{4}{*}{$\begin{array}{c}\text { Área ocupada } \\
\text { Pecuária } \\
\text { Agricultura } \\
\text { extrativismo }\end{array}$} & 3 & 1 & 3 & 3 & 3 & 5 & 3 & 3 & 5 & 1 & $1 / 5$ & 3 & 3 & 3 & $1 / 3$ & $1 / 3$ & $1 / 3$ & $1 / 5$ & $1 / 3$ \\
\hline & 3 & $1 / 3$ & 1 & $1 / 3$ & 3 & 5 & 3 & 3 & 5 & $1 / 5$ & $1 / 5$ & $1 / 3$ & 3 & 5 & 5 & 3 & 3 & $1 / 5$ & $1 / 5$ \\
\hline & 3 & $1 / 3$ & 3 & 1 & 3 & 5 & 5 & $1 / 3$ & 5 & $1 / 5$ & $1 / 3$ & 3 & 3 & 5 & 5 & $1 / 3$ & 3 & $1 / 5$ & $1 / 3$ \\
\hline & $1 / 3$ & $1 / 3$ & $1 / 3$ & $1 / 3$ & 1 & $1 / 3$ & 3 & $1 / 3$ & 5 & $1 / 5$ & $1 / 5$ & 3 & 3 & 3 & 5 & $1 / 3$ & $1 / 3$ & $1 / 5$ & 3 \\
\hline \multirow{3}{*}{$\begin{array}{l}\text { Área prioritárias para Conservação } \\
\text { Plano de Manejo } \\
\text { Conselho Gestor }\end{array}$} & 9 & $1 / 5$ & $1 / 5$ & $1 / 5$ & 3 & 1 & 3 & 3 & 9 & $1 / 3$ & 1 & 5 & 5 & 9 & 9 & 1 & 5 & 1 & 9 \\
\hline & 5 & $1 / 3$ & $1 / 3$ & $1 / 5$ & $1 / 3$ & $1 / 3$ & 1 & $1 / 3$ & 3 & $1 / 3$ & 5 & 3 & $1 / 3$ & 3 & 5 & $1 / 3$ & $1 / 3$ & $1 / 5$ & 5 \\
\hline & 5 & $1 / 3$ & $1 / 3$ & 3 & $1 / 3$ & $1 / 3$ & 3 & 1 & 5 & $1 / 3$ & $1 / 3$ & 3 & 3 & 3 & 5 & $1 / 5$ & 3 & 5 & 5 \\
\hline \multirow{3}{*}{$\begin{array}{l}\text { Secretaria de Meio Ambiente } \\
\text { Situação Fundiária } \\
\text { Desenho da UC }\end{array}$} & $1 / 3$ & $1 / 5$ & $1 / 5$ & $1 / 5$ & $1 / 5$ & $1 / 9$ & $1 / 3$ & $1 / 5$ & 1 & $1 / 3$ & $1 / 5$ & $1 / 5$ & $1 / 3$ & $1 / 3$ & $1 / 3$ & $1 / 9$ & $1 / 5$ & $1 / 5$ & $1 / 3$ \\
\hline & 3 & 1 & 5 & 5 & 5 & $1 / 3$ & 3 & 3 & 3 & 1 & 1 & 5 & 3 & 3 & 9 & 1 & 3 & 3 & 9 \\
\hline & 9 & $1 / 5$ & $1 / 5$ & 3 & 5 & 3 & $1 / 5$ & 3 & 5 & 1 & 1 & 5 & 3 & 5 & 9 & $1 / 3$ & 5 & $1 / 3$ & 9 \\
\hline \multirow{2}{*}{$\begin{array}{l}\text { Recursos Humanos e Infraestrutura } \\
\text { Ações de manejo }\end{array}$} & 3 & $1 / 3$ & 3 & $1 / 3$ & $1 / 3$ & 1 & $1 / 3$ & $1 / 3$ & 5 & $1 / 5$ & $1 / 5$ & 1 & $1 / 3$ & 1 & 3 & $1 / 5$ & $1 / 3$ & $1 / 3$ & 3 \\
\hline & 5 & $1 / 3$ & $1 / 3$ & $1 / 3$ & $1 / 3$ & $1 / 5$ & 3 & $1 / 3$ & 3 & $1 / 3$ & $1 / 3$ & 3 & 1 & 3 & 5 & $1 / 5$ & 3 & $1 / 9$ & 3 \\
\hline $\begin{array}{l}\text { Capacidade de monitoramento e } \\
\text { fiscalizacão }\end{array}$ & 5 & $1 / 3$ & $1 / 5$ & $1 / 5$ & $1 / 3$ & $1 / 5$ & $1 / 3$ & 1 & 3 & $1 / 3$ & $1 / 5$ & 1 & $1 / 3$ & 1 & 3 & $1 / 5$ & $1 / 3$ & $1 / 9$ & 3 \\
\hline \multirow{2}{*}{$\begin{array}{l}\text { Densidade Demográfica } \\
\text { Mediação de Conflitos }\end{array}$} & $1 / 3$ & 3 & 3 & 3 & $1 / 5$ & 1/9 & $1 / 5$ & $1 / 5$ & 3 & 1/9 & $1 / 9$ & $1 / 3$ & $1 / 5$ & $1 / 3$ & 1 & $1 / 9$ & $1 / 3$ & $1 / 5$ & 3 \\
\hline & 5 & 3 & $1 / 3$ & $1 / 5$ & 3 & $1 / 9$ & 3 & 9 & 9 & 1 & 3 & 5 & 5 & 5 & 9 & 1 & 3 & 3 & 9 \\
\hline \multirow{3}{*}{$\begin{array}{c}\text { Percentual da população na Pobreza } \\
\text { Economia Local } \\
\text { Prática Turisticas }\end{array}$} & $1 / 3$ & 3 & $1 / 3$ & 3 & 3 & $1 / 5$ & 3 & 5 & 5 & $1 / 3$ & $1 / 5$ & 3 & $1 / 3$ & 3 & 3 & $1 / 3$ & 1 & $1 / 3$ & 5 \\
\hline & 9 & 5 & $1 / 5$ & 5 & 5 & 1 & 5 & $1 / 5$ & 5 & $1 / 3$ & 3 & 3 & 9 & 9 & 5 & $1 / 3$ & 3 & 1 & 9 \\
\hline & $1 / 3$ & 5 & $1 / 5$ & 3 & 3 & $1 / 9$ & $1 / 5$ & $1 / 5$ & 3 & $1 / 9$ & $1 / 9$ & $1 / 3$ & $1 / 3$ & $1 / 3$ & $1 / 3$ & $1 / 9$ & $1 / 5$ & $1 / 9$ & 1 \\
\hline
\end{tabular}

Figura 2 - Matriz de Indicadores.

\begin{tabular}{|c|c|c|c|c|c|c|c|c|c|c|c|c|c|c|c|c|c|c|c|}
\hline \multirow[b]{2}{*}{ UNIDADES DE CONSERVAÇÃO } & \multicolumn{6}{|c|}{ Dimensão Ambiental } & \multicolumn{8}{|c|}{ Dimensão Institucional } & \multicolumn{2}{|c|}{ Dimensão Social } & \multicolumn{3}{|c|}{ Dimensão Econômica } \\
\hline & $\begin{array}{c}\text { Área com } \\
\text { Floresta / } \\
\text { Natural não } \\
\text { Vegetado }\end{array}$ & $\begin{array}{l}\text { Área } \\
\text { Ocupada }\end{array}$ & Pecuária & Agricultura & Extrativismo & $\begin{array}{c}\text { Área } \\
\text { prioritárias } \\
\text { para } \\
\text { Conservação }\end{array}$ & $\begin{array}{l}\text { Plano de } \\
\text { Manejo }\end{array}$ & $\begin{array}{l}\text { Conselho } \\
\text { Gestor }\end{array}$ & $\begin{array}{c}\text { Secretaria } \\
\text { Municipal de } \\
\text { Meio } \\
\text { Ambiente }\end{array}$ & $\begin{array}{l}\text { Situação } \\
\text { Fundiária }\end{array}$ & $\begin{array}{c}\text { Recursos } \\
\text { Humanos e } \\
\text { Infraestrutura }\end{array}$ & $\begin{array}{l}\text { Desenho } \\
\text { da UC }\end{array}$ & $\begin{array}{c}\text { Ações de } \\
\text { Manejo }\end{array}$ & $\begin{array}{l}\text { Capacidade de } \\
\text { Monitoramento e } \\
\text { fiscalização }\end{array}$ & $\begin{array}{l}\text { Densidade } \\
\text { Demográfica }\end{array}$ & $\begin{array}{c}\text { Mediação } \\
\text { de } \\
\text { Conflitos }\end{array}$ & $\begin{array}{l}\text { Extrema } \\
\text { Pobreza }\end{array}$ & $\begin{array}{c}\text { Economia } \\
\text { Local }\end{array}$ & $\begin{array}{l}\text { Práticas } \\
\text { Turísticas }\end{array}$ \\
\hline Resex do Ciricó & 2 & 1 & 1 & 1 & 1 & 1 & 3 & 1 & 3 & 2 & 2 & 1 & 2 & 2 & 2 & 3 & 3 & 1 & 2 \\
\hline Resex da Mata Grande & 3 & 2 & 3 & 2 & 2 & 1 & 3 & 2 & 3 & 3 & 3 & 2 & 3 & 2 & 1 & 1 & 3 & 2 & 3 \\
\hline Resex do Quilombo do Frechal & 3 & 1 & 2 & 1 & 1 & 1 & 3 & 1 & 1 & 2 & 2 & 1 & 1 & 2 & 2 & 1 & 3 & 1 & 2 \\
\hline Resex do Gururupu & 2 & 1 & 1 & 1 & 1 & 1 & 3 & 1 & 2 & 2 & 1 & 1 & 1 & 1 & 1 & 1 & 3 & 1 & 2 \\
\hline Reserva Biológica do Gurupi & 2 & 2 & 2 & 1 & 2 & 1 & 2 & 2 & 1 & 3 & 3 & 1 & 3 & 3 & 2 & 3 & 3 & 2 & 2 \\
\hline Parque Estadual do Bacanga & 2 & 3 & 1 & 1 & 3 & 2 & 2 & 2 & 1 & 2 & 2 & 2 & 2 & 2 & 3 & 2 & 2 & 1 & 2 \\
\hline Parque Estadual do Rangedor & 3 & 1 & 1 & 1 & 1 & 1 & 1 & 1 & 1 & 1 & 1 & 1 & 1 & 1 & 1 & 1 & 1 & 1 & 1 \\
\hline $\begin{array}{l}\text { Parque Nacional dos Lençois } \\
\text { Maranhenses }\end{array}$ & 2 & 1 & 1 & 1 & 1 & 1 & 2 & 2 & 1 & 2 & 2 & 1 & 2 & 2 & 2 & 2 & 3 & 1 & 3 \\
\hline Parque Estadual do Mirador & 2 & 3 & 3 & 2 & 1 & 1 & 3 & 3 & 1 & 3 & 3 & 3 & 3 & 2 & 2 & 3 & 3 & 2 & 2 \\
\hline Resex da Chapada Limpa & 3 & 1 & 1 & 2 & 2 & 3 & 3 & 1 & 1 & 2 & 2 & 1 & 2 & 1 & 2 & 1 & 3 & 2 & 2 \\
\hline rque Nacional das Chapada das Mesas & 2 & 1 & 2 & 1 & 1 & 1 & 3 & 2 & 3 & 2 & 2 & 2 & 2 & 1 & 2 & 2 & 3 & 1 & 3 \\
\hline
\end{tabular}

Figura 3 - Matriz de Comparação Pareada. 
Em suma, o método aplicado possibilitou a ponderação quantitativa das variáveis mediante correlações qualitativas, organizando e estabelecendo um modelo racional de combinação de dados, apresentado nas matrizes de indicadores e comparação pareada. Após a construção das matrizes, foi possível ordenar as alternativas de acordo com seus respectivos níveis de importância. Em seguida, os valores multiplicaram as matrizes de prioridades pelos vetores de atributos das alternativas. Para cada alternativa foi obtido a soma ponderada da importância relativa de cada atributo (Souza, 2013), referente aos vetores de prioridades e/ou significância, estes foram obtidos a partir das matrizes de comparações paritárias, com o autovetor de cada linha dividido pelo total, normalizado e calculado seguindo a equação abaixo (Ribeiro, 2017).

$$
A w=\lambda M A X^{W} \square \quad \begin{aligned}
& A \text { é a matriz de comparações paritárias; } \\
& w \text { é o autovetor principal, referente aos pesos; } \\
& \lambda \text { max é o autovalor principal de } A .
\end{aligned}
$$

Segundo Ribeiro (2017), o autovetor $w$ corresponde ao máximo autovalor ( $\lambda \max )$ da matriz de comparações paritárias. Dessa forma sintetiza-se os pesos que os critérios receberam baseado no julgamento estruturado, ou seja, o critério que receber maior peso será aquele que foi julgado como sendo o mais importante entre os autovetores de cada linha (nível de significância dos indicadores) (Tabela 1).

\begin{tabular}{|c|c|c|c|c|c|}
\hline DIMENSÃO & INDICADORES & $\begin{array}{l}\text { Média } \\
\text { geométrica } \\
\text { de cada } \\
\text { linha }\end{array}$ & $\begin{array}{l}\text { Autovetor de } \\
\text { cada linha } \\
\text { dividido pelo } \\
\text { total }\end{array}$ & $\begin{array}{l}\text { Soma de } \\
\text { cada } \\
\text { coluna da } \\
\text { matriz }\end{array}$ & $\begin{array}{l}\text { Autovetor da linha } \\
\text { multiplicado pela } \\
\text { soma de cada coluna }\end{array}$ \\
\hline \multirow{6}{*}{ Ambiental } & Área Ocupada & 1,409 & 0,071 & 13,000 & 0,925 \\
\hline & $\begin{array}{c}\text { Área Natural / Natural } \\
\text { não Vegetados }\end{array}$ & 0,463 & 0,023 & 67,000 & 1,566 \\
\hline & $\begin{array}{c}\text { Área Prioritária para } \\
\text { Conservação }\end{array}$ & 1,736 & 0,088 & 7,100 & 0,621 \\
\hline & Pecuária & 1,153 & 0,058 & 13,700 & 0,796 \\
\hline & Agricultura & 1,027 & 0,052 & 15,700 & 0,813 \\
\hline & Extrativismo & 0,915 & 0,046 & 23,700 & 1,094 \\
\hline \multirow{8}{*}{ Institucional } & Plano de Manejo & 0,726 & 0,037 & 30,600 & 1,122 \\
\hline & Conselho Gestor & 0,996 & 0,050 & 20,400 & 1,025 \\
\hline & $\begin{array}{l}\text { Secretaria Municipal de } \\
\text { Meio Ambiente }\end{array}$ & 0,293 & 0,015 & 93,000 & 1,374 \\
\hline & Desenho da UC & 1,683 & 0,085 & 8,700 & 0,739 \\
\hline & Recursos Humanos & 0,691 & 0,035 & 47,000 & 1,640 \\
\hline & Situação Fundiária & 2,001 & 0,101 & 13,900 & 1,409 \\
\hline & Ações de Manejo & 0,860 & 0,043 & 45,900 & 1,996 \\
\hline & $\begin{array}{c}\text { Capacidade de } \\
\text { Monitoramento }\end{array}$ & 0,630 & 0,032 & 70,200 & 2,233 \\
\hline \multirow{2}{*}{ Social } & Densidade Demográfica & 0,553 & 0,028 & 96,300 & 2,689 \\
\hline & Mediação de Conflitos & 1,874 & 0,095 & 7,800 & 0,734 \\
\hline \multirow{3}{*}{ Econômica } & $\begin{array}{c}\text { Percentual da população } \\
\text { na pobreza }\end{array}$ & 1,123 & 0,057 & 44,700 & 2,537 \\
\hline & Economia Local & 1,346 & 0,068 & 16,600 & 1,132 \\
\hline & Práticas Turísticas & 0,320 & 0,016 & 90,300 & 1,459 \\
\hline
\end{tabular}

Tabela 1 - Nível de significância dos indicadores.

Para analisar a consistência do método aplicado, avaliou-se a probabilidade dos julgamentos terem sido realizados ao acaso. Para tanto, utilizou-se a medida chamada de Razão de Consistência (RC), conforme Saaty e Vargas (2012). A avaliação da coerência do julgamento, visa validar o processo, qual seja: $\mathrm{RC} \leq 0,1=$ Julgamento coerente; $0,1<\mathrm{RC}<0,2=$ 
Julgamento questionável; $\mathrm{RC} \geq 0,2=$ Julgamento incoerente. Após a execução do processo acima, alcançou-se o valor de 0,068 da razão de consistência. Desse modo, afirma-se que os pesos calculados para o modelo proposto, tiveram julgamento considerado coerente.

Através do método AHP, foi possível atribuir pesos diferenciados a cada indicador utilizado na modelagem. Assim, os indicadores não terão a mesma importância conforme a matriz de indicadores e as operações de cruzamento apresentados na matriz comparada elaborada conforme indicado por Sahoo et. al. (2016). Após o cálculo da significância realizouse a ponderação dos indicadores, com base na média aritmética do coeficiente de relevância obtida como resultado da sintetização dos indicadores por dimensão (Tabela 2).

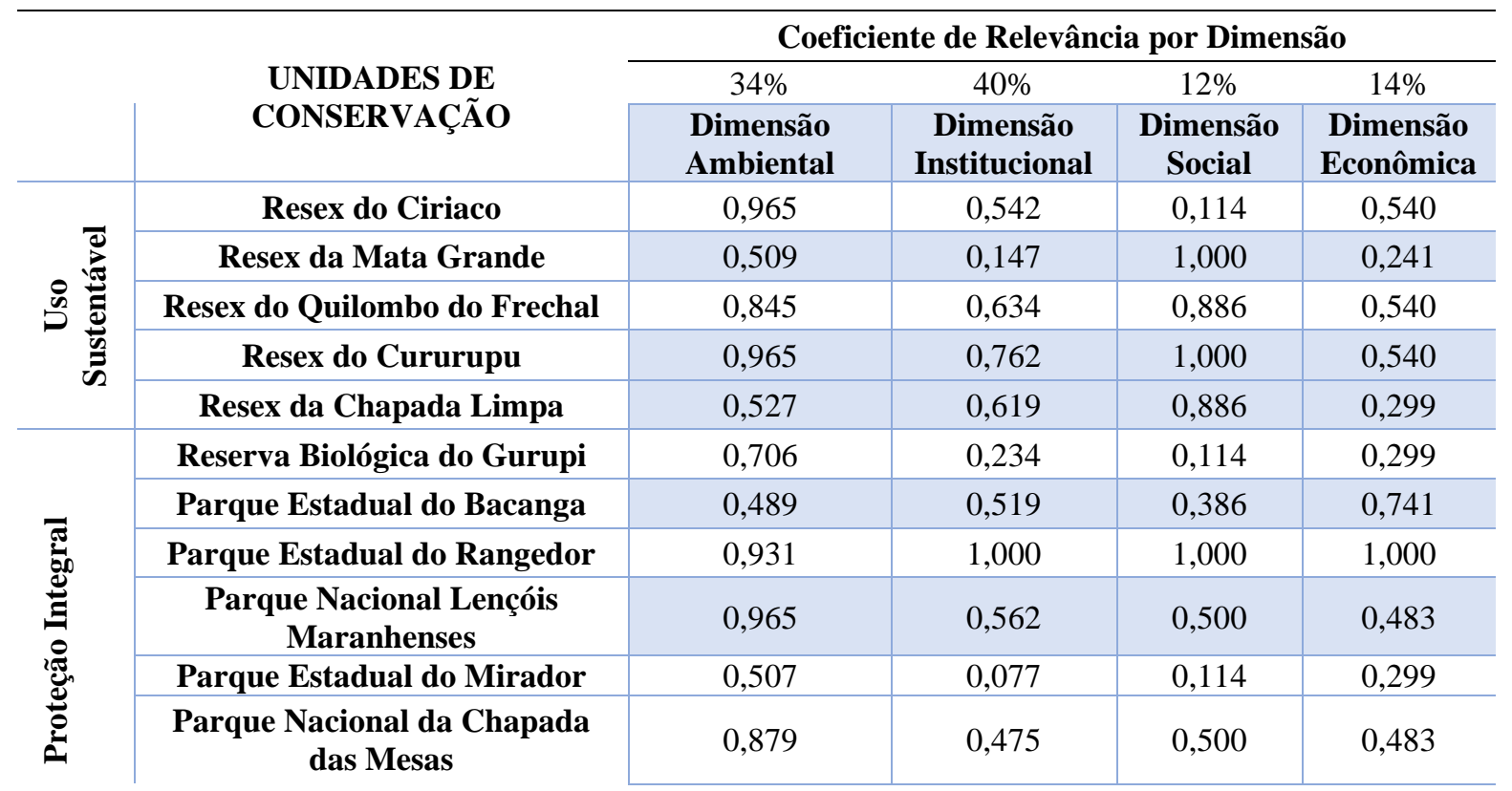

Tabela 2 - Coeficiente de relevância dos indicadores por dimensão

A partir dos procedimentos aplicados, estruturou-se a modelagem dos cálculos a partir da ponderação dos indicadores que resultou na construção do Índice de Efetividade das Unidades de Conservação (IFUC), composto pelos Sub - Índices: Índice de Conservação Ambiental (ICA) e Índice de Desenvolvimento Socioeconômico (IDS), expressa a seguir:

$$
\begin{aligned}
& \mathrm{ICA}=\frac{1}{n} \sum_{i=1}^{n} X i . F i \\
& I F U C=\Sigma \frac{I C A \cdot F_{1}+I D S . F_{2}}{n} \\
& \mathrm{IDS}=\frac{1}{n} \sum_{i=1}^{n} X i . F i
\end{aligned}
$$

A partir da construção dos índices sintéticos a análise do nível de efetividade das UCs, seguiu critérios hierárquicos conforme a escala de valorização nos quadros 4 e 5 .

\begin{tabular}{|c|c|c|}
\hline Nível & Variação (0 A 1) & Efetividade \\
\hline $\mathbf{1}$ & $>0,800$ & Satisfatório \\
\hline $\mathbf{2}$ & $0,551 \mathrm{~A} 0,800$ & Medianamente satisfatório \\
\hline $\mathbf{3}$ & $0,401 \mathrm{~A} 0,551$ & Pouco satisfatório \\
\hline $\mathbf{4}$ & $<0,400$ & Insatisfatório \\
\hline
\end{tabular}

Quadro 4 - Escala de valorização utilizada para mensurar o nível de efetividade das UCs. Fonte: Adaptado Padovan, 2001. 


\section{Nível 1: Satisfatório $(>0,800)$}

Indica que a UC conta com os requerimentos institucionais necessários para estabelecer um manejo eficiente, cumprindo com os objetivos da UC, com a execução de políticas públicas, ações de gestão e manejo que atendam as demandas da sociedade. Garante a preservação dos seus recursos naturais e culturais, integrando a comunidade local com a manutenção da qualidade de vida dos habitantes, além de demonstrar a existência de diferentes tipos de usos que estão alinhados com os objetivos da categoria e da UC.

Nível 2: Medianamente Satisfatório $(0,551$ A 0,800)

Indica que a UC conta com os requerimentos institucionais necessários desatualizados impossibilitando o estabelecimento de um manejo adequado. Contudo, os objetivos de criação da UC se encontram em patamares mínimos para a sua conservação, onde o modelo de gestão instituído cumpre com os objetivos da UC e garante a preservação dos recursos naturais e culturais. A área demonstra a existência de usos que apesar de serem vedados conforme a categoria da UC, não impedem o alcance dos objetivos da UC.

Nível 3: Pouco Satisfatório $(0,401$ A 0,550$)$

Indica que a UC não conta com os requerimentos institucionais mínimos necessários para estabelecer um manejo adequado. Contudo, o modelo de gestão instituído cumpre com os objetivos da UC e garante parcialmente a preservação dos recursos naturais e culturais. A área demonstra a existência de diferentes usos vedados conforme a categoria da UC, os quais dificultam o alcance dos objetivos da área protegida.

\section{Nível 4: Insatisfatório $(<0,400)$}

Indica que a UC se encontrar em situação de dificuldade na gestão dos seus objetivos e apresenta um baixo desempenho de retorno da política pública para a sociedade. A UC não contar com os requerimentos institucionais mínimos necessários para estabelecer um manejo adequado. A área demonstra a existência de diferentes usos vedados conforme a categoria da UC, os quais resultam em alto nível de alteração da paisagem, impedindo o alcance dos objetivos da área protegida.

Quadro 5 - Descrição do nível de efetividade de acordo com a escala de valorização.

Fonte - Adaptado Padovan, 2001; ICMBIO/WWF, 2017.

A classificação dos índices, utilizou a escala de valorização baseada em Faria et al. (1993) e adaptada por Padovan (2001). Nesse formato criou-se a hierarquização das variáveis, a partir do desenvolvimento de cenários respeitando a categoria, o nível de proteção e as características territoriais. A seguir, analisa-se o nível de efetividade das UCs em estudo no Maranhão.

\section{Resultados e discussão}

Conforme a abordagem metodológica e os procedimentos técnicos apresentados, identifica-se que das $11 \mathrm{UCs}$ em análise 18\% (02 UCs) apresentaram nível de efetividade satisfatório, 46\% (05 UCs) grau medianamente satisfatório, enquanto 9\% (01 UC) pouco satisfatório e 27\% (03 UCs) nível de efetividade insatisfatório (Figura 4).

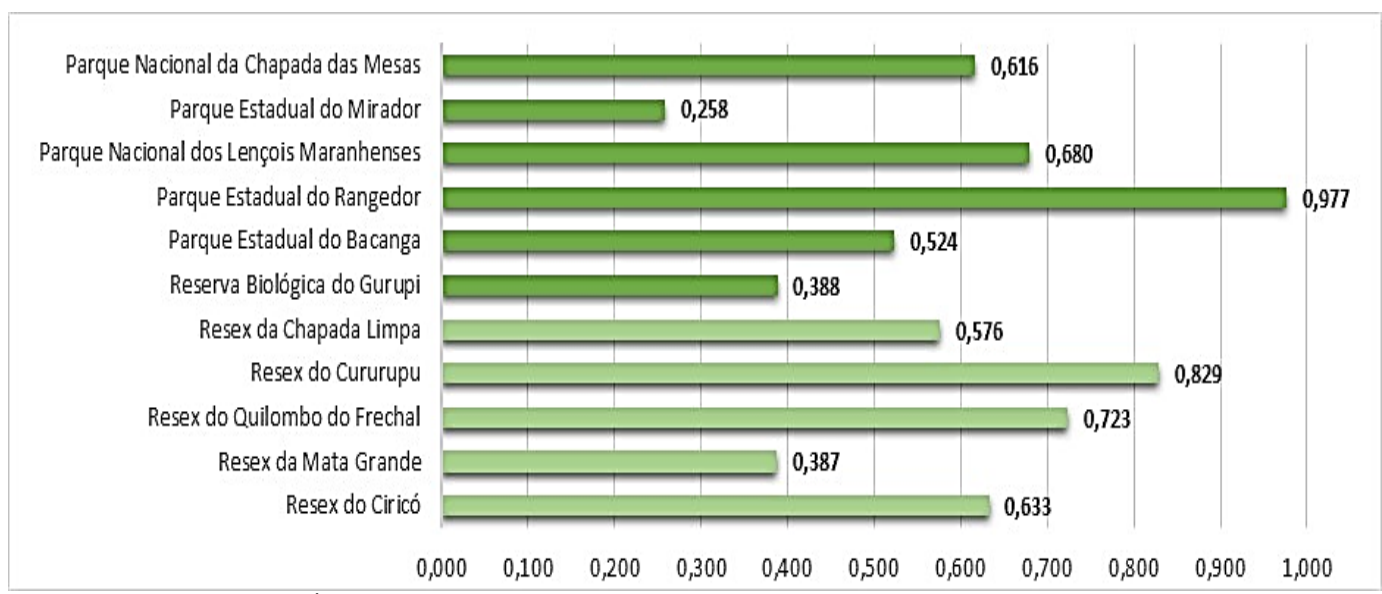

Figura 5 - Índice de Efetividade das Unidades de Conservação do Maranhão. 
A partir da análise espacial desenvolvida com base no IFUC, verifica-se 3 clusters conforme observado na figura 05 . O primeiro cluster com índice satisfatório está situado no extremo Norte do estado, sendo formado pelo PE do Rangedor e pelas Resex de Cururupu e Quilombo do Frechal. Essas UCs, demonstraram significativa preservação dos recursos naturais e culturais, integrando a comunidade local com a manutenção da qualidade de vida dos habitantes, além de demonstrar a existência de diferentes tipos de usos que estão alinhados com a categoria de proteção da UC.

O segundo cluster, registrou índice medianamente satisfatório abrangendo as UCs da região Leste e Sudoeste do Estado, composto pelas Resex do Ciriaco e Chapada Limpa, além dos Parques Nacionais dos Lençóis Maranhenses e Chapada das Mesas. De modo geral, estas UCs cumprem com seus objetivos e garantem parcialmente a preservação dos recursos naturais e culturais. No entanto, por não contarem com a infraestrutura necessária e por apresentarem a existência de diferentes usos da terra vedados pela legislação, alcançam parcialmente os objetivos da UC.

Em relação ao terceiro cluster, verifica-se índice insatisfatório. Este abrange a Resex da Mata Grande, Reserva Biológica do Gurupi e Parque Estadual do Mirador, localizadas na região Centro Sul e Oeste do Maranhão. Essas UCs, não contam com os requerimentos institucionais necessários para estabelecer um manejo adequado e reduzida capacidade de fiscalização, o que possibilita avanços de diferentes usos da terra vedados conforme a categoria da UC. 

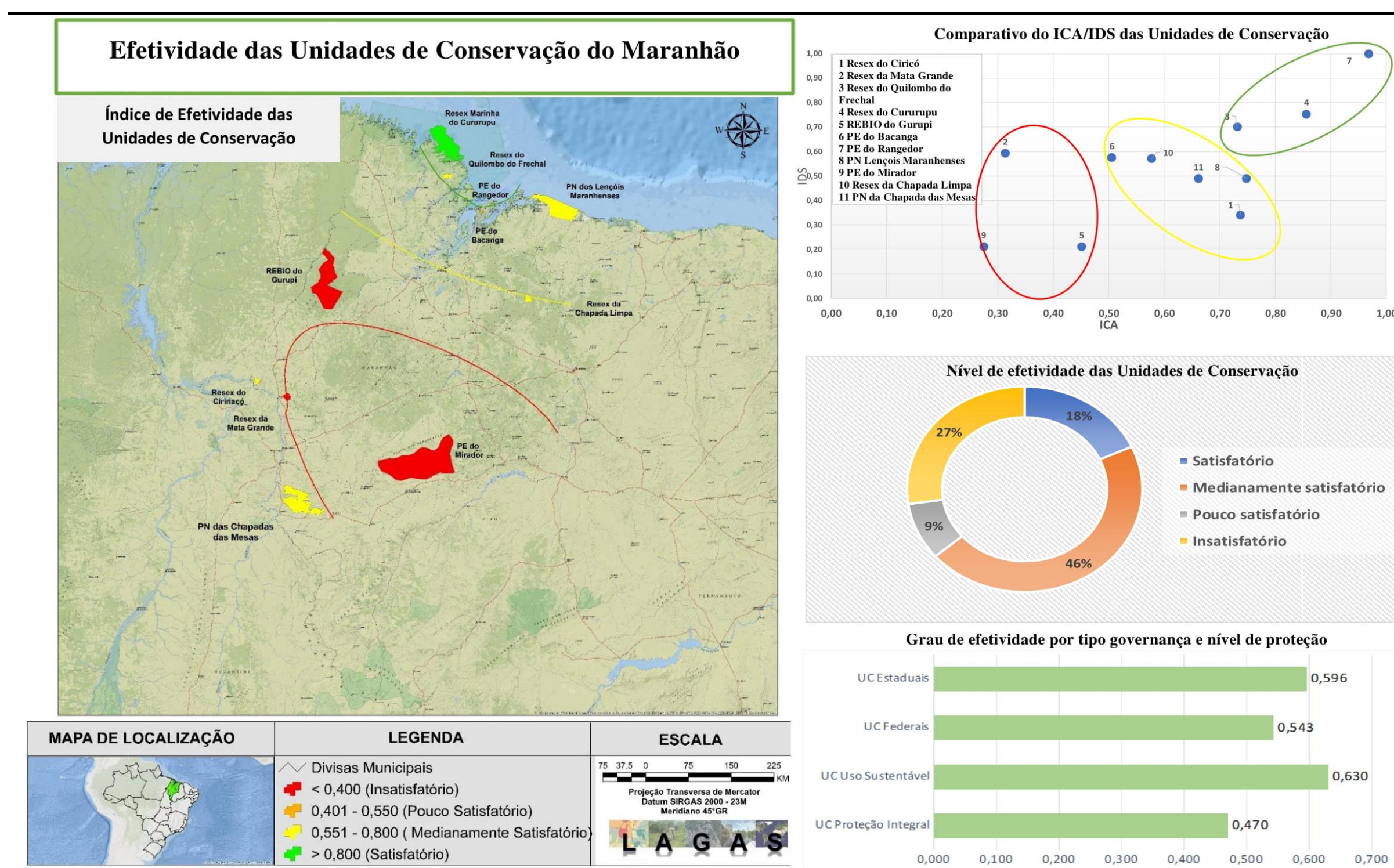

Figura 4 - índice de Efetividade das Unidades de Conservação do Maranhão. 
Considerando as UCs por governança, observa-se que as estaduais apresentaram nível de efetividade em média de 0,596, enquanto as unidades com governança federal $(0,543)$ alcançaram índice inferior. Ao passo que as UCs de uso sustentável, influenciadas pelo contexto social, alcançaram grau de efetividade superior as unidades com proteção integral. Conforme Unda e Etter (2019), isso significa uma oportunidade para reformular os usos da terra e considerar os bens e os diferentes tipos de usos ambientais que consideram os recursos naturais sem esgotá-los. Isso demostra a importância socioeconômica da reserva extrativista para essas comunidades tradicionais, por seus valores para a subsistência e o uso sustentável dos recursos naturais, benefícios e serviços ecossistêmicos às comunidades, como identificado em estudos desenvolvido pelo IBAMA (2007).

De modo geral, observa-se que as UCs localizadas ao Norte do Maranhão, onde o governo estadual e federal concentra grande parcela da sua estrutura administrativa, como na capital maranhense, as UCs possuem uma maior tendência a alcançar níveis mais elevados de efetividade. Essas UCs, mesmo com a pressão exercida por empresários, políticos e agentes imobiliários, possuem maior monitoramento e fiscalização por parte do poder público, da mídia e sociedade civil organizada. Mesmo nesse cenário, dados obtidos através de processamento de imagens de satélite (Masullo et al., 2018a) demonstraram boas evidências de que as UCs, alcançaram significativos níveis de conservação da biodiversidade, corroborando com os resultados obtidos por Geldmam et al. (2017), no que tange aos resultados das APs em nível mundial. Contribuindo com essa perspectiva Stoll-Kleemann e Job (2008) demonstram que a proteção da biodiversidade através das APs, está intrinsecamente relacionada a gestão local empática para sua efetivação, que é influenciada pela melhora dos meios de subsistência locais na medida do possível.

Para Lambin e Meyfroidt (2010), as políticas que influenciam o uso e cobertura da terra a partir de processos endógenos ao sistema socioeconômico, são construídas e formuladas seguindo diretrizes e interesses sobrepostos de diferentes atores locais, sejam eles formados pela comunidade local ou por instituições públicas e privadas. Desse modo, a dinâmica da cobertura florestal responde de maneira diferente entre os múltiplos territórios, devido às diferentes condições socioeconômicas e aos contextos biogeográficos, políticos e institucionais (UNDA e ETTER, 2019).

As UCs localizadas na região Leste e Sudoeste do Maranhão, apresentaram nível de efetividade medianamente satisfatória. Nessas UCs identifica-se em geral ausência ou precariedade dos instrumentos de planejamento e gestão da AP, contudo, essas UCs alcançam seus objetivos mesmo que parcialmente. Para Ervin (2006) a carência dessa estrutura de gerenciamento possibilita a ampliação de ameaças como a caça, invasões biológicas, extração de madeira e as invasões oriundas de atividades agrícolas. A deficiência existente na infraestrutura de monitoramento, recursos humanos $\mathrm{e}$ administrativa, fazem com que a UC dependa de fatores de proteção ${ }^{4}$, diante das ações de proprietários fundiários e promotores imobiliários, como as características físicas e econômicas da região.

Esse modelo é identificado em grande parcela nas UCs do Brasil (Diegues, 2000), o que diferencia a realidade brasileira, tendo em vista (McIntosh et al., 2018) a maior parcela das APs mundiais fora designada em locais que eram acentuadamente inadequados para a agricultura, o que impacta diretamente no nível de efetividade das UCs. Especificamente no Maranhão, as UCs que apresentaram nível de efetividade insatisfatório, localizam-se na região Oeste (Amazônia) e Centro Sul do estado. Essas 
UCs apresentam alto nível de alteração da paisagem, baixos indicadores socioeconômicos, além de não possuírem instrumentos de planejamento e gestão necessários para implementar ações de manejo necessários (Masullo et al., 2018b).

Essas UCs, são vistas como fronteiras agrícolas por fazendeiros e empresários locais, por possuírem características geológicas e geomorfológicas que potencializam o desenvolvimento das atividades ligadas ao agronegócio. A partir da realidade apresentada, constata-se que as UCs localizadas em ambiente de alta pressão e ameaças externas, em geral apresentam tendência para um menor nível de efetividade. Corroborando com essa perspectiva, Nolte et al. (2013) afirmam que as localizações de alta pressão, são particularmente desafiadoras, por facilitar o acesso e deslocamento, e por conseguinte invasões e conflitos nessas APs.

Nesse caso específico, as características físicas das UCs tornam-se um fator de risco $^{5}$, por se tornarem um chamariz para pressões políticas que impossibilitam a ampliação da fiscalização dos órgãos gestores, bem como criam entraves para elaboração e implementação dos instrumentos necessários para otimizar o manejo.

Assim como Roque et al. (2019) observa-se que os conflitos e ameaças as UCs no bioma amazônico maranhense são comumente associadas às atividades exploratórias e à conversão de áreas florestais nativas, enquanto no Cerrado se relacionam com questões fundiárias e a conversão de áreas florestais em áreas de pastagem, agricultura e silvicultura (especialmente de eucalipto e soja) e nas regiões costeiras, as preocupações estão frequentemente associadas à especulação imobiliária.

Outro aspecto a se considerar é que assim como identificado por Coad et al. (2019) em nível mundial, identificamos que apenas $18 \%$ das UCs em estudo relataram recursos humanos e infraestrutura adequada, onde o principal fator limitante relatado, são os reduzidos investimentos e orçamentos disponível. Para Jones et al. (2018) esse é um dos maiores problemas que as APs enfrentam, considerando que a ausência de recursos adequados reflete diretamente na capacidade de se evitar a perda e degradação do habitat natural.

Assim como no presente estudo, pesquisas desenvolvidas por Joppa et al. (2009) e Pfaff (2013) constataram que áreas de maior pressão possibilitam menos proteção. De acordo com os autores supracitados, é menos provável que em APs com alta pressão externa produzida por políticas regionais direcionadas pelo mercado, possam alcançar os seus objetivos. Isso é consolidado pela precária infraestrutura, recursos humanos e financeiros das UCs.

O contexto evidenciado no Maranhão assim como Sacre et al. (2019) em estudo sobre as APs em áreas de fronteiras, constata-se não só uma interrelação entre as escalas local e regional, mas uma dependência. Isso amplifica a importância da criação e expansão das UCs, contudo, percebe-se que o nível de implementação apresentado não é suficiente para garantir a efetividade de políticas públicas e, por conseguinte a real efetividade desses territórios.

\section{Conclusões}

O presente estudo, buscou apresentar uma metodologia capaz de ponderar quantitativamente variáveis mediante correlações qualitativas, organizando e estabelecendo um modelo relacional de combinação de dados. Diferentemente dos métodos de avaliação como SAMGE, METT e o RAPPAM, que se basearam predominantemente em conhecimentos focados especificamente nos gestores das APs. O 
IFUC utilizou dados quantitativos com base secundária e processamento de imagens de satélite, atrelados a dados primários qualitativos obtidos através de gestores, conselheiros e comunidade local.

Para avaliação e monitoramento das UCs, o método aplicado apresenta-se como um instrumento sistemático de monitoramento alternativo aos utilizados atualmente em escala estadual. A abordagem utilizada para o desenvolvimento do IFUC, contempla em sua concepção sub - índices compostos por indicadores distribuídos por dimensão (ambiental, institucional, social e econômica). Esse modelo apresenta uma forma de demonstrar os indicadores sintetizados e/ou individualizados, particularizando os diversos contextos existentes, bem como atenua a subjetividade das interpretações, através do estabelecimento de uma hierarquia de soluções com a quantificação dos atributos e suas correlações.

Considerando as escalas de aplicação de diferentes técnicas, os resultados alcançados na presente pesquisa, demonstraram nível satisfatório, apresentando conclusões similares aos obtidos por metodologias já consolidadas e aplicadas no Brasil e no mundo como WWF (1999); RAPPAM (2005-2010-2015) e SAMGe (2017). Considerando a metodologia aplicada em relação ao RAPPAM e o SAMGE, ressalta-se que estes métodos de avaliação da efetividade possuem escala nacional, enquanto o IFUC possui escala estadual. Contudo, a metodologia proposta, apresentou entre outras vantagens, reduzida utilização de recursos financeiros, rápida aplicação, além de abranger UCs que nunca haviam sido avaliadas por outros métodos como RAPPAM e SAMGe. Entre as 11 UCs do Maranhão em análise, somente 36\% (4) foram avaliadas por métodos como o RAPPAM e SAMGE. Isso decorre da ausência de dados específicos, ou mesmo pela dificuldade em interpretar as informações disponíveis pelos gestores locais.

Constatou-se que apesar do IFUC, considerar as particularidades das UCs do Maranhão, a estrutura conceitual e metodológica criada com suas adaptações pode ser utilizada para o desenvolvimento de sistemas de indicadores, ligados ao monitoramento e planejamento territorial de outras UCs. Ressalta-se, que essa metodologia não tem a pretensão de substituir os métodos utilizados atualmente, mas sim configurar esse instrumento como complementar para apoiar os gestores estaduais, na ampliação do conhecimento e como mecanismo de reflexão sobre a busca constante para evolução metodológica.

A priori, verifica-se que o esforço a ser feito para a implementação técnica e operacional, concerne no investimento em capacitação de recursos humanos, direcionados a atualização e eventuais adaptações dos indicadores a serem utilizados, de acordo com a dinâmica territorial de cada recorte espacial. Isso, possibilita a redução da subjetividade na construção de índices sintéticos, diminuição de custos operacionais, além de ampliar a quantidade de UCs avaliadas, aumentando a confiabilidade e a capacidade de reprodução da avaliação do nível de eficácia da gestão.

Assim como Getzner et al. (2012), o presente estudo ao considerar a influência do contexto e escala regional sobre as UCs do Maranhão, verificou-se que existe a possibilidade de não empregar ferramentas de avaliação em profundidade para identificar os pontos fracos da gestão, bem como agentes tensores que influenciam a dinâmica local. Em contrapartida, observa-se que a utilização de instrumentos metodológicos, baseados em variáveis primárias e secundárias, possibilita a elevação do quantitativo de UCs avaliadas por ampliar disponibilidade, confiabilidade e periodicidade de atualização dos dados, bem como otimizar a análise qualitativa e comparativa. 
Em escala regional, pode-se alcançar resultados abrangentes com o fornecimento de recomendações detalhadas com base em avaliações rápidas, que produzam informações sobre questões cruciais. Dessa forma, reduz-se a necessidade de uma avaliação dispendiosa, além da utilização das ferramentas de monitoramento a longo prazo. No entanto em nível nacional, seria necessário a aplicação de mais testes para avaliação do método.

Compreender essa relação entre as escalas nacional e regional, bem como sua influência no contexto local, possibilita maior coerência e melhores resultados nas ações de manejo, além de otimizar o delineamento de estratégias para enfrentamento das diferentes pressões e ameaças. Por fim, verifica-se que as circunstâncias e o contexto ambiental, socioeconômico e político, influenciam não só a criação desses territórios protegidos, mas também as ações de manejo e consequentemente a consecução dos seus objetivos.

\section{Notas}

1 - Contexto: Avalia os usos e os aspectos socioeconômicos, evidenciando o cenário atual; Insumos: Avalia a infraestrutura e recursos humanos existentes na UC;

Resultados: Evidencia as ações desenvolvidas e os resultados obtidos de acordo com os objetivos da UC; Planejamento: avalia informações sobre os objetivos, amparo legal e planejamento territorial;

Processos: avalia os instrumentos de planejamento, tomada de decisão e monitoramento realizados na UC. 2 - Os tópicos e questões a serem tratadas são definidas antecipadamente; o entrevistador decide a sequência das perguntas durante a entrevista.

3 - O entrevistador conhece os temas sobre os quais tem de obter reações por parte do inquirido, mas a ordem e a forma como serão introduzidos, seguem critérios pré-estabelecidos.

4 - Fatores de proteção são potenciais auxiliadores do enfrentamento a ameaças e desafios, que se constituem em características individuais, relações de vínculo e circunstâncias do próprio contexto que amparam a resiliência, como, por exemplo, a existência de políticas públicas de assistência social, recuperação socioeconômica e características ambientais ou culturais (Souza, 2011).

5 - Fatores de risco são situações ou eventos estressores que predispõem diferentes territórios, pessoas ou comunidades às desestruturações e crises (Marchezini e Forini, 2019).

\section{Referências}

ARTAZA-BARRIOS, O. H.; SCHIAVETTI, A. Análise da Efetividade do Manejo de duas Áreas de Proteção Ambiental do Litoral Sul da Bahia. Revista de Gestão Costeira Integrada 7(2). 2007. p. 117-128.

ARGYRIOU, A.V. et al. GIS multicriteria decision analysis for evaluation and mapping of landscape deformation neotectonics: A case study from Crete. In: Geomorphology, 262 -274. 2016.

CARRERA, J. R. Evoluación de indicadores para el monitoreo de concesiones forestales en Peten, Guatemala. Tesis Mag. Scientiae. CATIE. Turrialba, Costa Rica. 2000.

$\mathrm{COAD}, \mathrm{L}$. et al. Widespread shortfalls in protected area resourcing undermine efforts to conserve biodiversity. Front Ecol Environ. 2019. p. $1-6$.

COHEN, L. et al Research methods in education. Routledge. $6^{\mathrm{a}}$ ed. Londres. 2007. 656p.

DIEGUES, A. C. S. O mito moderno da natureza intocada. Núcleo de Apoio à Pesquisa sobre Populações Humanas e Áreas Úmidas Brasileiras 3.a ed. Hucitec. USP. São Paulo. 2000. 161p. FARIA, H. H.de. Eficácia de gestão de unidades de conservação gerenciadas pelo Instituto Florestal de São Paulo, Brasil. Dissertação (mestrado) - Universidade Estadual Paulista, Faculdade de Ciências e Tecnologia. Presidente Prudente. 2004. 401p.

FERREIRA, M. C. Iniciação à análise geoespacial: teoria, técnicas e exemplos para geoprocessamento. Editora Unesp. $1^{\circ}$ ed. São Paulo. 2014. 343p. 
GELDMANN, J. et al. Mapping change in human pressure globally on land and within protected areas. Conservation Biology, 28. 2014. p. 1604-1616.

A global analysis of management capacity and ecological outcomes in terrestrial protected areas. Conservation Letters. 2017. p. 1 - 10.

HOCKINGS, M. et al. Protected area management effectiveness. In: Worboys, Lockwood, Kothari, Feary, Pulsford (eds). Protected Area Governance and Management. ANU Press, Canberra. 2015. p. $889-928$.

IBAMA, Instituto Brasileiro do Meio Ambiente e dos Recursos Naturais Renováveis. Efetividade de gestão das unidades de conservação federais do Brasil. Ibama, WWF-Brasil. Brasília. 2007. 96p.

ICMBio - Instituto Chico Mendes de Conservação da Biodiversidade. Avaliação comparada das aplicações do método Rappam nas unidades de conservação federais, nos ciclos 2005-06 e 2010. Instituto Chico Mendes de Conservação da Biodiversidade, WWF-Brasil. Brasília: ICMBio. 2011. 134p.

IRVING, M. et al. Construção de governança democrática: interpretando a gestão de parques nacionais no Brasil. In: IRVING, Marta de Azevedo (Org.). Áreas protegidas e inclusão social: construindo novos significados. Fundação Bio-Rio: Núcleo de Produção Editorial Aquarius. Rio de Janeiro 2006. 225p.

JONES K. R, et al. One-third of global protected land is under intense human pressure. Science 360. 2018. p. 788-791.

JOPPA LN, et al. High and far: Biases in the location of protected areas. PLoS ONE 4. 12. 2009. 8273.

LAMBIN, E. F.; MEYFROIDT, P. Land use transitions: Socio-ecological feedback versus socio-economic change. Land Use Policy. 27. 2010. p. 108-118.

MCNEELY, J. A. At least do no harm: poverty and protected areas in China. Discussion paper for the CCICED. Protected Areas Task Force. 2004.

MARCHEZINI, V.; FORINI, H. A. Dimensões sociais da resiliência a desastres. Redes (Santa Cruz do Sul. Online), v. 24, n. 2, 2019. p. 09-28.

MARINELLI, C. E. De olho nas unidades de conservação: Sistema de Indicadores Socioambientais para Unidades de Conservação da Amazônia Brasileira. Instituto Socioambiental. São Paulo. 2011. 12p.

MASUllO, Y. A. M. et al. O passado e o presente das unidades de conservação do Maranhão, Brasil. Revista Caminhos de Geografia, Uberlândia, v. 19, n. 66. 2018a. p. 250-268. MASULLO, Y. A. M. et al. Socioeconomic dynamics of the protected areas of Maranhão. CONFINS (PARIS), v. 38, 2018b. p. 1-13.

MOREAUX C. et al. Can existing assessment tools be used to track equity in protected area management under Aichi Target 11? Biological Conservation 224. 2018. p. 242-247.

NELSON, A. K.; CHOMITZ. M. Effectiveness of Strict vs. Multiple Use Protected Areas in Reducing Tropical Forest Fires: A Global Analysis Using Matching Methods. PLOS ONE. Volume 6. Issue 8. 2011.p. 01-14.

NOLTE, C. et al. Governance Regime and Location Influence Avoided Deforestation Success of Protected Areas in the Brazilian Amazon. Proceedings of the National Academy of Sciences 110 (13). 2013. p. 4956-4961.

OESTREICHER, J.S. et al. Avoiding deforestation in Panamanian protected areas: an analysis of protection effectiveness and implication for reducing emissions from deforestation and forest degradation. Global Environmental Change, 19. (2009). p. 279-291. PADOVAN, M. P. Formulacion de um estandar y um procedimento para la certificacion del manejo de áreas protegidas. Centro Agronomico Tropical de Investigacion y Ensenanza. Turrialba, Costa Rica. 2001.

PAFF A, et al. Governance, location $\&$ avoided deforestation from protected areas: Greater restrictions can have lower impact, due to differences in location. World Dev, in press. 2013. 
RIBEIRO, B. A. Proposta para revelar as preferências de comitês de especialistas a partir do método AHP: uma aplicação ao setor elétrico. Tese (doutorado). Pontifícia Universidade Católica do Rio de Janeiro. Departamento de Engenharia Elétrica. Rio de Janeiro. 2017. 115p.

ROQUE, M. P. B. et al., Effectiveness of Arguments Used in the Creation of Protected Areas of Sustainable Use in Brazil: A Case Study from the Atlantic Forest and Cerrado. Sustainability. 2019. p. 1-16.

SACRE E, et al. The context-dependence of frontier versus wilderness conservation priorities. Conservation Letters. 2019

SAATY, T. L. Método de Análise Hierárquica. $1^{\text {a }}$ ed. São Paulo: McGraw-Hill. 1991.

SAATY, T.L.; VARGAS, L. G. Models, Methods, Concepts \& Applications of the Analytic Hierarchy Process. $2^{\text {a }}$ ed. New York: Springer. 2012.

SAHOO. S. et al. Environmental vulnerability assessment using Grey Analytic Hierarchy Process based model. In: Environmental Impact Assessment Review. 145-154. 2016.

SILVA, O. D. A. Estratégia do Programa Áreas Protegidas da Amazônia para avaliar a Efetividade das Unidades de Conservação. Tese de Doutorado. Universidade de Brasília UnB, Centro de Desenvolvimento Sustentável - CDS. 2016. 212p.

StOLTON, S. et al. Reporting Progress in Protected Areas a Site-Level Management Effectiveness Tracking Tool: second edition. World Bank/WWF Forest Alliance published by WWF, Gland, Switzerland. 2007. 21p.

STOLL-KLEEMANN, S; JOB. H. The Relevance of Effective Protected Areas for Biodiversity Conservation: An Introduction. GAIA17. 2008. p. 186-189.

STOLL-KLEEMANN, S. Evaluation of management effectiveness in protected areas: Methodologies and results. Basic and Applied Ecology 11. 2010. p. 377-382.

UNEP-WCMC; IUCN. Protected Planet Report 2018. UNEP-WCMC, IUCN and NGS: Cambridge UK; Gland, Switzerland; and Washington, D.C., USA. 2018. 70p.

UNDA, M.; ETTER, A. Conservation Opportunities of the Land Restitution Program Areas in the Colombian Post-Conflict Period. Sustainability, MDPI, Open Access Journal, vol. 11(7). P. 1-19. 2019.

WATTS, J. E. M. Marxan.io user guide: A web app for systematic conservation planning. Australian Research Council Centre of Excellence for Environmental Decisions. The University of Queensland. 2016. 25p.

WWF Brasil - World Wide Found for Nature. Áreas Protegidas ou Espaços Ameaçados: O Grau de Implementação e a vulnerabilidade das Unidades de Conservação federais Brasileiras de Uso Indireto. Org. DE SÁ, Rosa M. Lemos; FERREIRA, Leandro. Brasília. 1999. 32p.

WWF Brasil - World Wide Found for Nature. Avaliação da gestão das unidades de conservação: métodos RAPPAM (2015) e SAMGE (2016). WWF Brasil. 1ª ED. Brasília. 2017. $127 \mathrm{p}$. 